little village of New Harmony who knew about Say, and who were distinctly of the opinion that his residence in their village sheds lustre on its history. The village library is an admirable one, housed in a beautiful building, and among the treasures of the library are certain of Say's manuscripts, among others, one written upon the day of his death.-L. O. Howard, Washington, D. C.

\title{
NOTE ON THE GENERIC TITLE TRIFURCUIAA.
}

BY A. RADCliffe GROTE, HILDESHEIM, GERMANY.

In my "Descent of the Pierids," Jan., 1900, I have used Trifurcula, Staud., Iris., VII., 56, for a genus of Andean Pierids, but this name is preoccupied in the Lepidoptera by Zeller, 1848 , Staud. \& Rebel, Cat. II., p. $22 \mathrm{I}$.

Staudinger states (l. c.) that he had at first named the genus Piercolias, so this name, though open to criticism, should be used for the Pierid genus with the type huanaco, Staud. The morphological value of the neurational character of the primaries of Piercolias, which led Staudinger to choose the name Trifurcula, does not seem to have been appreciated by him. The gradual progress of $R_{2}$ towards the apices, and of $\mathrm{M}_{2}$ towards the Radius, brings these branchlets in juxtaposition.

\section{SPINNING METHODS OF TELEA POLYPHEMUS.}

In reply to the query suggested by Prof. Grote, in the April number of the Entomologist (page i ro), with reference to the spinning methods of Telea, I have discussed the subject with Dr. Fletcher, whose opinion is that only some of the cocoons are so suspended, but recent search has decided me that in this locality this is the case with the majority.

On April and I found two cocoons on a small willow bush, one suspended, with the leaves firmly attached to the stem; the other had been spun between the overhanging sides of a large leaf that had fallen across the limb, thus forming a complete canopy, but the cocoon was firmly fastened to the twig with a lot of silk. Diligent search amongst the leaves on the ground failed to reveal any fallen cocoons. On April 8th I found two cocoons, both suspended on a wild currant bush, and though there was a pile of dry straw lying against the 
bush, which would have afforded a splendid harbour for the larva, yet no signs of any cocoon or silk were found on it.

In all cases where I have bred Telea they have attached the Jeaves and cocoon to the stem with a silken band, which usually entirely surrounds the stem for a distance of over an inch.

I have collected from 2 to 4 dozen of these cocoons each winter for the past three years, and occasionally have found them only very insecurely attached, but in every case where they have been spun amidst a bunch of fallen leaves, they have had the added protection of being fastened to some twig.

Last fall I discovered two cocoons, from which the moths had prematurely emerged, and these were both securely fastened to the end of the twigs.

I shall read with interest all contributions on the subject, as this peculiarity may only apply to western America.

J. Wm. Cockle, Kaslo, B. C.

\section{BOOK NOTICES.}

A List of North American Lepidoptera, and Key to the Literature of this Order of Insects.-By Harrison G. Dyar, Ph. D. Bulletin of the United States National Museum, No. 52. Washington, D. C., Government Printing Office, I902. I vol. 8vo.; pp., xix., 723.

Students of Lepidoptera throughout North America have been looking forward with great interest to the publication of Dr. Dyar's List, and have been full of hope that it would afford them an authoritative and final settlement of the nomenclature of our butterflies and moths, which for many years has been in a state of change and instability. We fear that this hope will be seriously disappointed. The changes in many instances appear so arbitrary, the multiplication of genera so inordinate, the absolute extinction of many familiar names so far from necessary, that the ordinary student will feel much hesitation in adopting this List as his guide, and unlearning so much that he has known regarding the names of his specimens. He will naturally be inclined to think that the List cannot be final, and that it will be safer for him to wait for further developments before he changes a large proportion of the labels in his cabinet and fills his notebooks with new names. 